\title{
Desrespeito e Revolta
}

MATIIAS ISER"

\section{Resumo}

Uma crítica social frutífera precisa questionar, também, se as ações ou condições sociais que inicialmente provocam apenas sentimentos difusos de mal-estar ou de vergonha, não deveriam, de preferência, suscitar revolta. Uma das mais frutíferas propostas teóricas para dar conta dessa tarefa é a Teoria do Reconhecimento de Axel Honneth, com a qual ele pretende substituir a ênfase habermasiana em nossas práticas comunicativas como fundamento da Teoria Crítica. Contudo, nessa abordagem inovadora, é exatamente a forte ênfase de Honneth no autorrelacionamento individual (como núcleo de uma teoria formal do Bem) que conduz a uma incorreta interpretação por parte dele dos principais aspectos da revolta capazes de provocar o avanço. Neste artigo, eu analiso mais precisamente a contribuição que a ideia de uma autorrelação bem-sucedida (como suposto telos) realiza dentro da teoria do reconhecimento, porém, ressaltando suas limitações.

Palavras-chave: Teoria do reconhecimento. Autorrelação. Revolta social. Axel Honneth.

\footnotetext{
* Senior Research Fellow e Membro da Diretoria do DFG-Grupo Colegiado de Pesquisa no Departamento de Ciências Sociais da Johann Wolfgang Goethe-Universität Frankfurt/Main (Alemanha).E-mail: m.iser@em.uni-frankfurt.de
} 


\section{Disrespect and rebellion ${ }^{1}$}

\section{Abstract}

A fertile social criticism must also question whether the actions or social conditions that initially cause only diffuse feelings of discomfort or shame should ideally also raise rebellion. One of the most fruitful theoretical proposals for dealing with this task is Axel Honneth's theory of recognition, by means of which he intends to replace the Habermasian emphasis on our communicative practices as the foundation of Critical Theory. However, in such innovative approach is exactly Honneth's strong emphasis on individual 'relations-to-self' (as the core of a formal Theory of the Good) that leads him to a misleading interpretation of the main aspects of rebellion that are able to bring on advancements. In this article, I analyze more precisely the contribution that the idea of a successful 'relation-to-self' (as a supposed telos) performs within the theory of recognition, though pointing out its limitations.

Keywords: Theory of recognition. Relation-to-self. Social rebellion. Axel Honneth.

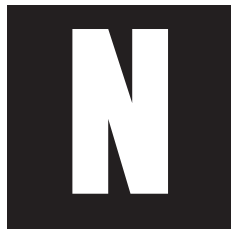

os últimos tempos, a discussão pública se vê novamente confrontada com uma crescente erupção de reações emocionais negativas como fúria e raiva. Basta pensar nos protestos maciços no contexto (ou como consequência) da "primavera Árabe" ou nos adolescentes baderneiros nas banlieues francesas. A Crítica da Sociedade faz bem em levar essas emoções explosivas muito mais a sério do que tem feito até agora. Porém, enquanto fúria, ódio - e mesmo a raiva que, por vezes, daí surge - normalmente resultam do fato de que os seres humanos sentemse lesionados (na sua autoestima), o sentimento de revolta remete, sempre - por mais desorientado que, no caso concreto, possa ser - à violação de uma reivindicação moral. Essa diferença central entre uma doença do Eu e um desrespeito moral instruem também o presente artigo.

\footnotetext{
${ }^{1}$ Tradução de Giovani Agostini Saavedra.
} 
Crítica da sociedade é, em essência, sobretudo a verificação reflexiva da revolta; de uma revolta com potencial para conduzir a um avanço moral $^{2}$. No entanto, mesmo os sentimentos de revolta têm valor meramente heurístico, porque as expectativas que estão em sua base - embora, no mais das vezes, de forma apenas implícita - tanto podem ser justas como também injustas. Revolta, enquanto reação emotiva que pretende mostrar o injusto, exige, portanto, a prova argumentativa da sua adequação. Ao mesmo tempo, ela traz consigo, também, diferentemente do caso do ódio ou da fúria, um conhecimento, pelo menos implícito, de que não só contra mim, mas também a lesão de outros representa um motivo para revolta. Com referência às expectativas normativas, em razão das quais eu me sinto lesionado, eu consigo, então, assumir uma postura representativa e mais impessoal (Strawson, 1978, p. 217). De tudo isso, decorre que uma Teoria da Sociedade crítica também precisa questionar se ações ou relações sociais que inicialmente provocam somente sentimentos difusos de malestar ou de vergonha, não deveriam, de preferência, suscitar revolta.

Uma das mais frutíferas propostas teóricas para dar conta dessa tarefa é a Teoria do Reconhecimento de Axel Honneth, com a qual ele pretende substituir a ênfase habermasiana em nossas práticas comunicativas como fundamento da Teoria Crítica. Sob dois aspectos a Teoria do Reconhecimento deveria tornar possível uma análise mais clara: em primeiro lugar, desde seus primeiros trabalhos, Honneth não estava convencido do argumento de que os seres humanos, em um nível motivacional, deveriam se revoltar, sobretudo em razão de relações de entendimento desfiguradas, ou seja, da falha em honrar as pretensões de validade. Pelo contrário, no seu entendimento, somente experiências de desrespeito, que ameçam a identidade, podem esclarecer de forma adequada a resis-

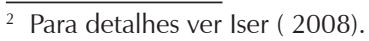


tência social. Em segundo lugar, a análise crítica deveria poder repousar sobre um nível conteudístico de substratos do reconhecimento, ao invés de sobre meros procedimentos. Com esse novo fundamento normativo, por conseguinte, Honneth quer examinar em sociedades, em última instância, em que medida elas possibilitam aos sujeitos que nelas vivem um bem sucedido autorrelacionamento.

Tão inovadora quanto essa proposta teórica possa ser, é exatamente a forte ênfase no autorrelacionamento individual (como núcleo de uma teoria formal do Bem) que conduz a uma incorreta interpretaçãopor parte de Honneth dos aspectos principais da revolta capazes de provocar progresso. Neste artigo, eu analiso, por isso, mais precisamente, a contribuição que a ideia de uma autorrelação bem-sucedida (como suposto telos) realiza dentro da teoria do reconhecimento, porém, ressaltando suas limitações.

No que segue, eu procederei em dois passos: primeiramente, eu situo a teoria Honnethiana no debate contemporâneo sobre a forma mais adequada de crítica da sociedade, porque ela dá uma resposta especialmente ambiciosa às quatro tarefas centrais de qualquer crítica (1). Após, eu vou delimitar, em quais aspectos a teoria honnethiana preenche essas tarefas e onde se podem apontar déficits (2).

\section{Sobre a ideia de uma Teoria Crítica da Sociedade}

Na discussão contemporânea sobre a forma mais adequada de teoria crítica da sociedade Honneth - assim como o seu professor Jürgen Habermas ${ }^{3}$ - assume uma posição intermediária, que ele próprio caracteriza como reconstrutiva (Honneth, 2011, p. 23). Normalmente, distinguem-se dois campos concorrentes, o da crítica interna e o da crítica 
externa. Propostas da crítica interna (ou imanente) relacionam-se a valores ou normas que a sociedade mesmo já exige.Tal crítica quer referir-se aos motivos dos sujeitos que se revoltam. Entretanto, formas de crítica interna vêem-se confrontadas com o Problema, em que medida uma crítica sem distância radical é capaz de superar o Status quo. Por isso, críticas externassão referidas a critérios que desviam-se do Cânon de valores dominante da sociedade criticada. Uma tal crítica externa pode apelar, dentre outros, a Deus, "à razão", à nossa "verdadeira" essência, a necessidades ou interesses "objetivos" até agora desconhecidos ou pura e simplesmente a concepções de uma outra cultura. Exatamente porque a crítica externa, nesse sentido, vem "de fora", coloca-se, todavia, a pergunta de se ela é capaz de convencer os seus destinatários ou se, simplesmente, busca convertê-los.

Contudo, essa tradicional contraposição entre "interna" vs. "externa" contribui muito pouco para a compreensão da crítica da sociedade; na verdade, pelo contrário, dificulta-a muito mais. Todas as formas de crítica referem-se - ainda que somente de forma implícita - a elementos internos de uma prática, a fim de ganhar um ponto de vista, que torna possível uma certa distância desta prática - e, neste sentido, é externa. A verdadeira pergunta é, portanto, a quais elementos da praxis esses críticos se referem.

A forma de teoria crítica da sociedade a que visa Honneth, assim como Habermas, tenta, então, explicitar, para além da dicotomia de "externa" e "interna", expectativas normativas que se fundamentam nas formas de vida humana como tal (e não simplesmente em determinadas práticas) e, assim, valeria para todas as sociedades. O exame da estrutura básica das expectativas lesionadas deveria, por um lado, abastecer a teoria crítica da sociedade com crítérios ricos em conteúdo. Por outro lado, os sentimentos que se colocam em função da frustração dessas expecta3 Para uma comparação detalhada ver Iser (2008). 
tivas podem, de fato, ser inteiramente reprimidos, mas nunca completamente apagados. Honneth herda com isso a ideia central da tradição do hegelianismo de esquerda, a saber: que a razão prática não se esgota em um simples dever-ser, mas sim já é efetiva na realidade social. A crítica reconstrutiva - e também a variante de Honneth da mesma - entende-se, por um lado, como um empreendimento normativo explícito, porém, por outro, não quer apenas descobrir social teoreticamente a estrutura das expectativas irreversíveis, mas, em última instância, também identificar as causas, pelas quais, através da sociedade moderna, essas expectativas são (estruturalmente) frustradas.

Porém, porque se deveria impor a carga de prova de identificar expectativas irreversíveis, que sempre superam o status quo? Para responder a essa pergunta, eu gostaria de, no que segue, diferenciar e discorrer brevemente sobre quatro tarefas da teoria crítica da sociedade, cujo especial desempenho a crítica reconstrutiva acredita aqui apresentar. Eu designo essas tarefas, para facilitar a compreensão, com as seguintes abreviaturas: Expectativas (1.1), Progresso (1.2), Crítica (1.3) e Resistência.

\subsection{Expectativas}

Qualquer crítica da sociedade objetiva, ao menos implicitamente, mover seus destinatários para ações modificadoras. Dado que ela precisa apelar aos motivos desses destinatários, tem que proceder, de uma forma ou de outra, "internamente", referindo-se às expectativas normativas centrais que já estão contidas nas práticas sociais. Para evitar a acusação de Status quo, a teoria crítica da sociedade reconstrutiva quer descobrir, por sob as normas divergentes de culturas e épocas, expectativas normativas irreversíveis ou "quasi-transcendentais", às quais corresponde uma forma determinada de revolta. 
Honneth parte do princípio - assim como a maioria das teorias do reconhecimento - de que os seres humanos são, fundamentalmente, dependentes do reconhecimento de outros seres humanos (e, em última instância, também da sociedade): somente através das reações de outros concretos e da interiorização de valores e normas socias os sujeitos alcançarão uma concepção daquilo, que eles, de fato, são e querem ser. Àquele a quem se apresenta uma imagem unilateral ou até negativa de si mesmo ou quem é, simplesmente, ignorado, deve ser difícil afirmar-se ou seguir seu próprio projeto de vida sem uma persistente falta de confiança em si mesmo. Somente o reconhecimento possibilita uma condição positiva de liberdade. Ele é, por conseguinte, "uma necessidade humana fundamental" (Taylor, 1993, p. 13). Essa dependência fundamental do reconhecimento expressa-se, no entanto, histórica e culturalmente de diversas formas. Quando Honneth, no decorrer de sua reconstrução da Eticidade moderna, distingue, a partir de Hegel, três esferas do reconhecimento, a saber "Amor", "Direito" e "Solidaridade" (atualmente "Performance"4), de modo algum ele descreve essa tríade específica como necessidades encontradas a-historicamente. Pelo contrário, ela marca o resultado de mudanças históricas (Honneth, 2003, p. 309 e ss.; 2003a, p. 163). No nível concreto da análise, Honneth julga, assim, proceder antropologicamente, não no sentido, segundo o qual ele suporia exatamente dessa forma, supratemporalmente, necessidades ou características fixas. Honneth quer, antes, obter critérios substantivos, através dos quais ele reconstrói cada princípio normativo que se fixou no interior da Modernidade - e, de fato, somente na Modernidade - cuja forma de reconhecimento devemos fundamentadamente esperar uns dos outros.

\footnotetext{
$\overline{{ }^{4} \text { No original: Leistung (Nota do Tradutor) }}$
} 


\subsection{Progresso}

Porque não é suficiente, para uma crítica da sociedade, simplesmente aplicar critérios normativos já existentes, se se quer evitar a mácula de arbitraridade, esses critérios precisam ser fundamentados de forma plausível. Para evitar, em um primeiro nível, a acusação de arbitrariedade, a crítica pode fundamentar-se a partir dos valores centrais da própria cultura. Porém, em um segundo nível, é necessário perguntar: por que se deveriam privilegiar esses valores em contraposição a outros, como, por exemplo, aqueles da Idade Média? Pode até ser que não se consiga resolver esse problema. Quando não se consegue identificar qualquer critério do progresso moral, não faz sentido continuar insistindo em uma tal concepção. Mas é evidente, no entanto, que seria melhor para a força de convencimento de uma crítica, se a validade de seus fundamentos não estivesse referida simplesmente a um ponto de vista contingente.

Na minha interpretação, a teoria crítica do reconhecimento de Honneth tem a pretensão de apresentar uma tal concepção formal de progresso. Ele pretende, com isso, complementar a reconstrução horizontal das expectativas normativas (enfatizada em Honneth, 2011) com uma vertical. Para tanto, ele precisa provar que a forma moderna específica de reconhecimento, que inequivocamente carrega as feições do universalismo, igualitarismo e do individualismo, em contraposição a antigas formas do reconhecimento, apresenta um ganho em racionalidade e, por fim, também em progresso moral - apesar de todas as deformações que são passíveis de crítica nas práticas modernas.

O progresso deveria, além disso, ser intepretado como desenvolvimento de um conteúdo normativo que, desde o início, estava conectado com a estrutura normativa das relações de reconhecimento - a qual não é colocada, simplesmente, de fora, externamente. Por fim, essa lógica do 
progresso deveria esclarecer em qual direção as ordens contemporâneas do reconhecimento deveriam progredir.

\subsection{Crítica}

A tarefa própria de toda crítica consiste em indicar inconvenientes que fazem pressão dentro da sociedade. Certamente, uma crítica pode se contentar em chamar a atenção para aspectos secundários. Porém, de uma crítica da sociedade, espera-se que permita reconhecer as principais injustiças e patologias. Porque, então, as expectativas normativas que explicitam a crítica da sociedade reconstrutiva, ao mesmo tempo, devem formar o núcleo de nossa moral, e essa forma da crítica exige, de fato, compreender o defeitos centrais da sociedade. A utilização de um conceito fundamental "harmônico" como o do reconhecimento não deveria conduzir, assim, diretamente a uma interpretação ideológica do presente. Uma vez que a conceitualidade da teoria ajusta-se às expectativas normativas fundamentais dos atingidos, deveria, pelo contrário, lançar uma luz ainda mais viva sobre as patologias e injustiças.

\subsection{Resistência}

Cada crítica da sociedade precisa de destinatários, pois não é uma práxis autosuficiente, mas sim visa a um esclarecimento teórico, que deveria desaguar numa mudança prática. Até a famosa metáfora da crítica social como "correio de garrafa" (Flaschenpost) $)^{5}$ designa uma mensagem dirigida a alguém, ainda que em um futuro possível. Se o panfleto críti-

5 Flaschenpost significa, literalmente, "correio de garrafa", "mensagem de garrafa" ou "carta de garrafa" e consiste em uma metáfora criada pelos representantes da primeira geração da Escola de Frankfurt para designar o que seria a essência da Teoria Crítica: a idéia aqui seria a de que, como as cartas enviadas em garrafas, a mensagem da Escola de Frankfurt não teria um destinatário específico, mas seria "jogada ao mar" a espera de "potenciais leitores" (Nota do Tradutor). 
co fosse queimado, ao invés de ser enviado como "correio de garrafa", a crítica seria, talvez, um sinal de resistência espiritual interna, porém, negaria o seu objetivo próprio. Não pode ser indiferente para a crítica da sociedade, se ela é capaz de produzir efeitos.

Dado que Honneth acredita, como representante da proposta teórica reconstrutiva, ter descoberto o mecanismo normativo central, ele sugere possuir uma especial sensibilidade para [determinar] em que ponto as expectativas normativas são tão massivamente frustradas que revolta e resistência são muito prováveis, quando não "garantidas" (Honneth, 2003b, p. 275). A teoria do reconhecimento, até aqui, só logra detectar a latente ou já sentida revolta e autoesclarecer-se. Onde existir uma discrepância entre revolta esperada e revolta observada, o crítico deve ser capaz de explicar teoricamente esta diferença, referindo-se aos obstáculos sociais e políticos que estão no caminho do sentir e da articulação de uma tal revolta. Que uma injustiça não seja reconhecida como óbvia pode significar, apenas, que as pessoas tenham crescido em uma tradição repressiva ou que estão subjugadas a outras estruturas de poder, as quais tornam impossível ou, pelo menos, difícil ou perigoso contra elas protestar.

\section{A Teoria Crítica entre doença e revolta}

No que segue, eu gostaria de, pelo menos, esboçar, em que medida a teoria de Honneth tem êxito em resolver satisfatoriamente as quatro tarefas expostas de crítica da sociedade. Ao mesmo tempo, indicarei os respectivos déficits resultantes, no meu entendimento, do fato de seu conceito de reconhecimento ser compreendido, em última análise, de forma excessivamente psicológica e, ao invés de ressaltar o fenômeno da revolta, referido a um injusto moral, normalmente, ressaltar o fenômeno da doença, o qual simplemente mostra que o próprio sentimento 
de amor-próprio (possivelmente narcisístico) foi ferido. Por essa razão, sugiro um conceito de reconhecimento deontológico, o qual permite a superação desse déficit. No contexto deste artigo, em função da limitação de espaço, minha discussão só poderá ser esboçada em linhas gerais (de forma mais pormenorizada, ver Iser, 2008).

\subsection{Sobre a reconstrução de expectativas normativas}

Para uma teoria que quer ter o sentimento de revolta em sua base, as expectativas sobre as quais ela apoia sua análise são de crucial importância. Ao reconstruir, como Honneth, expectativas de reconhecimento, podem-se acentuar dois aspectos em diferente medida: o psicológico e o normativo.

Quem experiencia reconhecimento (Anerkennung) não é apenas reconhecido (erkannt) como pessoa com determinadas características, mas também, dessa forma, confirmado positivamente, ainda que isso não [deva] se esgote[ar] em puras palavras ou expressões simbólicas (Honneth 2003, p. 319) ${ }^{6}$. Somente como atitude que se manifesta para além de expressões explícitas, tanto faciais como gestuais assim com em ações de apoio, o reconhecimento é fidedigno. O reconhecimento de uma pessoa vem acompanhado da consciência de estar obrigado a ter uma determinada atitude, assim como obrigado a realizar determinadas ações: o seu status normativo é reconhecido, por exemplo, como sujeito com direitos iguais. A esse reconhecimento, não somente porque determina nossos direitos e deveres recíprocos, deve-se dar um peso grande. $\mathrm{O}$ reconhecimento deve também ser tão importante, porque - como já se tratou acima - satisfaz uma profunda necessidade psicológica. Em atos de desrespeito, não é somente o status moral da vítima que é lesionado, mas também a sua integridade psíquica como principal aspecto da moral.

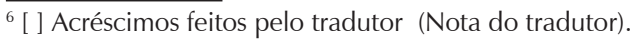


É, então, de especial significado a questão de como se compreende a relação entre necessidade psíquica e justificação normativa. Essa determinação tem consideráveis efeitos sobre a forma da crítica da sociedade. Num primeiro momento, pode-se sentir inclinado a dar prioridade ao fenômeno da necessidade psíquica, porque ele precede à possibilidade de se prestar contas com argumentos.

Por conseguinte, uma criança, antes de aprender a se relacionar com o mundo em uma orientação proposicional, desenvolve uma relação afetiva substancial de reconhecimento para com suas pessoas de referência primárias. Poder-se-ia, então, acreditar que o bebê desenvolvesse já expectativas normativas, antes de aprender a explicitá-las na linguagem e, com isso, se posicionar dentro do espaço de razões. Porém, eu acredito que, assim, o conceito do normativo é excessivamente ampliado. Para uma melhor explicação, no que segue, eu diferencio três níveis de necessidades que podem dar razões para expectativas, a saber: necessidades basais-corporais (1); necessidades interativas (2) e "necessidades normativas" (3). Eu utilizo aqui "normativo" no sentido específico de prescrições morais e não naquele sentido mais amplo, segundo o qual também deveres racionais são normativos (tais como argumentar consistentemente). Embora todos os três níveis normativos sejam relevantes, somente o terceiro é lugar daquelas expectativas normativas, as quais a teoria crítica da sociedade tenta explicitar.

No nível basal-corporal (1), trata-se, no caso de recém-nascidos, de seres que têm necessidades objetivas - tais como alimentação - e, portanto, dependem de um curador. Porém, em um primeiro momento, não faz parte da expectativa do recém-nascido, que as satisfaçamos com base em determinadas razões. Porém, se prologamos nosso cuidado por um determinado período, pode ser que o bebê crie, de fato, a expectativa, de que nós continuemos a cuidar de suas necessidades. Essas necessidades são, 
prima facie, normativamente relevantes, porque nós também as temos e as apreendemos como normativamente relevantes. Porém, essas expectativas do bebê não são exatamente estruturadas internamente de forma normativa. A falta do apoio esperado pode, então, conduzir ao desgosto ou ao ódio, mas não à revolta. Ainda que, em um sentido mais abrangente, se pudesse falar que bebês teriam "razões" para construir essas expectativas, na verdade, eles não podem tomar consciência dessas razões como razões (Maclntyre, 2001, p. 85). Somente pessoas reflexivas e que usam a linguagem têm a capacidade de atribuir uma razão aos bebês.

O outro extremo apresenta "necessidades" genuinamente normativas do nivel (3). No entanto, trata-se aqui de um fenômeno derivado. Porque nós, como seres formados culturalmente, necessariamente criamos expectativas normativas, temos uma necessidade de que elas sejam correspondidas. Essas expectativas justificam, com isso, que os participantes conheçam uma norma intersubjetiva e, portanto, que eles se mantenham nela reciprocamente de forma justificada. O conceito de normativo implica que se possa errar ou ainda que se possa, conscientemente, violar uma norma. Se essa "necessidade" por tratamento adequado - cujo conteúdo varia historicamente de forma considerável - não é satisfeita, os atingidos podem não só reagir com tristeza, desgosto ou ódio, mas, dadas situações favoráveis, também com revolta, o que marcou o ponto de partida do presente artigo. Aquele, que se revolta, situa-se na recusa de algo, sobre o que acredita ter uma justificada pretensão. Seguramente, a teoria do reconhecimento assume que essas pretensões são passíveis de serem adequadamente formuladas como pretensões de reconhecimento. Porém, tais pretensões apontam prioritariamente para comportamentos exigíveis de terceiros e não, primariamente, para a satisfação de necessidades de reconhecimento ${ }^{7}$.

\footnotetext{
$\overline{{ }^{7}}$ Na seção 2.2 adiante, eu discuto em detalhes como podem emergir pretensões normativas de necessidades.
} 
As necessidades interativas do nível (2) assumem, então, uma interessante posição intermediária: elas não são ainda normativamente estruturadas e, mesmo assim, já se referem a outras pessoas. Embora recémnascidos possam não ter nenhuma necessidade receber afeto pelos motivos corretos, bem a têm de que lhes seja concedida uma determinada forma de cuidado amoroso. Isso mostra-se, em particular, na sua necessidade por proximidade corporal e segurança. Além disso, os seres humanos deveriam se diferenciar dos outros primatas (e sobretudo dos outros mamíferos), pelo fato de poderem identificar-se com outros seres humanos, pois são capazes de conhecer neles, do mesmo modo, seres intencionais e dotados de capacidade espiritual (Tomasello, 2002, p. 17). Ao contrário, os outros primatas são por um lado, eles mesmos, seres intencionais e causais, mas não entendem o mundo em conceitos intencionais e causais (Tomasello, 2002, p. 32). De fato, parece que Honneth quer falar sempre e em todas as passagens sobre expectativas normativas, onde se tratem de expectativas que se dirigem a outros seres humanos e a sua atitude acentuadamente afetiva. Já se mostrou, no nível basal-corporal (1), que podemos desenvolver expectativas perante outro alguém. Honneth quer, com isso, situar experiências normativas já na fase da primeira infância e antes de qualquer uso da linguagem e da possibilidade de justificação.

Isso tem, porém, consideráveis consequências para o conceito de reconhecimento utilizado. Naturalmente, pode-se compreender reconhecimento como uma necessidade pré-linguística e interativa. Porém, enquanto o sujeito reconhecido não adquirir alguma consciência do seu status normativo, uma tal necessidade, como já demonstrado no nível basal-corporal (1), será relevante normativamente, porém, não será ainda estruturada normativamente. Todavia, é precisamente a essas últimas expectativas, as quais por isso, descrevi como necessidades somente em um sentido metafórico, que a teoria reconstrutiva crítica da sociedade precisa se referir, para resgatar a tese, segundo a qual os Standards normativos, por ela identifica- 
dos, produzem efeitos internamente na forma de expectativas normativas (implícitas). Reconhecimento, nessa compreensão estreita e explicitamente normativa, indica, com certeza, uma coerência com o sentimento positivo, segundo o qual alguém preocupa-se comigo em uma atitude positiva ou reage afirmativamente às minhas qualidades específicas.

$\mathrm{E}$, mesmo assim, esse não é ainda um sentimento positivo normativo, porque, para isso, necessita de uma referência a normas (e aos seus valores fundantes), a partir das quais determinados deveres surgem. Esses precisam ser linguisticamente articuláveis, embora não ainda necessariamente já articulados. Uma atitude de reconhecimento - sobre a qual já me referi anteriormente - possui o caráter de meta-ação, que se dá a entender para mim de forma que eu possa contar, em razão de um dos meus próprios valores, com ações positivas correspondentes. O próprio Honneth admite também, que nós deveríamos deixar o reconhecimento criar domicílio no 'Reino das razões', de forma que ele não venha a ser, sem que se perceba, uma ação essencialmente moral (Honneth 2003, p. 322). As necessidades pré-linguísticas dependem da interação, mas, sobretudo, situam-se para além do "Reino as Razões"; elas precisam primeiro ser integradas nele.

Para ilustrar o caráter de um precursor, poder-se-ia falar também, no que diz respeito aos níveis (1) e (2), de protonormatividade; por exemplo, em vista do desgosto de um recém-nascido acerca do fato de que as suas necessidades não foram satisfeitas. E, com certeza, a experiência afetiva amorosa representa um recurso importante para nossa futura identidade moral motivacional. Mas essas linhas de continuidade na formação de nossas expectativas normativas não deveriam obscurecer o fato de que somente dentro do espaço de razões se trata, em sentido próprio, de relações estruturadas de reconhecimento normativas. Uma teoria crítica da sociedade deveria, por isso, repousar sobre um conceito deontológico de 
reconhecimento, ou seja, sobre uma concepção que coloque os deveres recíprocos no centro.

Certamente, as necessidades até então reprimidas ou transitórias desconsideradas no nível basal-corpóreo (1) e no nível interativo (2) que, no que segue, vou referir simplificadamente como necessidades materiais - podem, através de novas perpectivas, que "abrem novos mundos" ${ }^{\prime \prime}$, mostrar-se de forma mais clara, qualificando-se, assim, como candidatas para exigências fundamentadas e, consequentemente, como expectativas no nivel normativo genuíno. Quando um sujeito registra, por exemplo, que reagiu com revolta à desconsideração em relação a suas necessidades ou suas características, e não com indiferença ou puro desgosto, então, abre-se para ele a perspectiva de estar de posse de uma exigência moral que precisa ser fundamentada perante os outros. Somente quando o sujeito pode introduzir razões de porque suas necessidades basais-corporais ou interativas deveriam ou até mesmo precisam ser satisfeitas pelos outros, tratam-se de expectativas normativas (ainda que essas possam ser injustificadas). Frequentemente, fundamenta-se a revolta no fato de que o sujeito acredita ter sido desrespeitado em seu status normativo; o status que a ele pertence em função de um determinado valor dentro de um relacionamento específico. Nesse sentido, podem o desgosto e o ódio se transformar em revolta, quando se compreende (se acredita compreender) que se dispõe de uma exigência justificada, a qual foi violada.

\footnotetext{
${ }^{8}$ Aqui o autor faz referência indireta ao termo „Crítica-que-abre-novos-mundos" („Welterschlie-ende Kritik"), cunhado por Honneth para designar a forma de crítica típica da primeira geração da escola de Frankfurt. Ver, a esse respeito, principalmente: Honneth, Axel. Über die Möglichkeit einer erschlie-enden Kritik. Die „Dialektik der Aufklärung" im Horizont der gegenwärtigen Debatten über Sozialkritik. In: Honneth, Axel. Das Andere der Gerechtigkeit. Aufsätze zur praktischen Philosophie. Frankfurt am Main: Suhrkamp, 2000 (Nota do tradutor).
} 
Ao vincular tão estritamente o conceito de reconhecimento ao sentimento de revolta, não diferencio as diversas dimensões do reconhecimento no sentido da vulnerabilidade psíquica, mas sim no sentido das devidas obrigações de reconhecimento. Também do ponto de vista de conteúdo chega-se a outras conclusões. Então, delitos como aquele do estupro não deveriam, como propõe Honneth, ser atribuídos à esfera do amor, porque (ainda que como um ponto extremo negativo) corroem a autoestima, mas sim à esfera do direito, porque podemos exigir de todos os outros, de forma coativa, que se abstenham dessas ações ${ }^{9}$.

Honneth mesmo, ao longo do desenvolvimento de sua obra, acentuou de forma diferente os aspectos psicológicos e normativos ${ }^{10}$. Em um primeiro momento, Honneth extrai as três dimensões do reconhecimento das várias formas de autorrelação, a saber: autoconfiança (amor), autorespeito (direito) e autoestima (solidaridade). Ao longo desses três níveis deveria aumentar gradualmente a força-do-Eu do indivíduo (Honneth, 1992, p. 151). A formação e a segurança de um autorrelacionamento bem-sucedido mostra, então, o aspecto psíquico do reconhecimento. Porque essa primeira dimensão de análise dominava nos anos noventa, muitos intérpretes acreditavam que Honneth quisesse derivar das necessidades antropológicas profundas os critérios críticos, mais ou menos diretamente. Em reação a essa crítica, ele tenta, então, pelo final desta década, não só sistematizaras alusões reunidas na sua obra principal Luta por reconhecimento (1992) sobre os respectivos direito[s] e deveres de cada esfera especifica (Honneth, 2001, p. 105), mas também responder à pergunta, quem aqui, de fato, deve a quem. No entanto, essa moral do reconhecimento é novamente, depois, diferenciada como segundo nível de análise, ou seja: qual dimensão do relacionamento consigo mesmo, respectivamente, ela assegura na

\footnotetext{
${ }_{9}^{9}$ Para mais detalhes, ver Iser, 2010, p. 402.

${ }^{10}$ De forma mais detalhada, ver Iser, 2008, p. 177-193.
} 
forma de um aspecto material - e não, primariamente, a partir do critério de quem aqui deve alguma coisa. O nível psicológico, que mostra o ponto de referência de uma teoria formal da vida boa, permanece, então, para Honneth, decisivo. Por fim, nas três formas, deveria ser reconhecido como valioso, respectivamente, um determinado aspecto da pessoa autônoma. Ainda que essa ideia de uma "percepção avaliativa" das características humanas já fundamentava de forma implícita os escritos dos anos noventa, Honneth somente desenvolve de forma explícita este terceiro nível no início do novo século. Assim, devem-se diferenciar tantas formas de ação moral, quanto há valores a ser reconhecidos por sujeitos humanos (Honneth, 2001, p. 13). A teoria de Honneth indica três níveis de análise: o nível forma da autorrelação a ser protegida, o dos direitos e deveres implícitos, e o dos valores consolidados. Não obstante, os deveres resultam, principalmente, da proteção da autorrelação individual e essa proteção é, em última instância, também o objetivo para o qual a moral efetivamente existe. Tão importante quanto essa percepção possa ser, Honneth a unilateraliza. Antes de apresentar esse ponto em mais detalhes, na seção 2.3, eu gostaria de, primeiramente, salientar o papel de uma bem-sucedida autorrelação para a concepção honnethiana de progresso.

\subsection{Critérios do progresso moral}

Como confrontar a objeção de Richard Rorty, que afirma tratar-se de um puro autoengano, quando se fala de critérios a-históricos do progresso moral? Segundo Rorty, consideramos nossa compreensão "liberal“ da moral necessariamente melhor, mas se trata, aí, de nada mais do que uma ilusão confortante, porque, com a mudança dos objetivos das práticas humanas, também mudam os conteúdos da moral ${ }^{11}$. Diante desse desafio, uma teoria crítica da sociedade precisa extrair critérios substanciais

11 Por exemplo: Rorty, 2000, p. 358. 
de progresso a partir da estrutura da revolta moral. Tais critérios ilustram o desenvolvimento de uma moral universalista, igualitária e individualista como resultado de um processo de aprendizagem. Ao mesmo tempo, eles afastam o perigo de que uma concepção de progresso - como tão frequente na história - aplaine o caminho, de forma etnocêntrica, para políticos do (Neo-) Imperialismo.

Honneth sugere dois critérios com os quais se pode comparar ordens do reconhecimento também de forma diacrônica. Há progresso, por conseguinte, quando mais seres humanos-ele chama esse critério de "inclusão social" (a) - em mais características ou aspectos de si mesmos - a esse ele denomina "individualização" (b) - forem reconhecidos, porque poderão, dessa forma, alcançar um grau superior de autonomia ${ }^{12}$. Com isso, mostra-se que a teoria formal da vida boa somente é relevante para o segundo critério do progresso.

(a) Inclusão Social

Ainda em Luta por reconhecimento, Honneth queria compreender o princípio moral universal de igual respeito no sentido de uma "obrigação empírica". Segundo esta posição, cada indivíduo somente poderá experienciar, então, suficiente reconhecimento, se ele mesmo reconhecer todos os outros como iguais. Essa tese sustenta-se sobre uma marca estrutural das relações de reconhecimento. Somente nos sentimos honrados, quando nós mesmos valorizamos a pessoa que nos honra. Portanto, assim é a tese, preciso reconhecer todos aqueles por quem eu, por outro lado, quero ser reconhecido, de forma relevante para mim. (Honneth, 1992, p. 64). Porém, disso não resulta nem uma coação para a universalidade, nem para a igualdade. Em uma ordem social hierárquica, cada nobre precisa reconhecer apenas alguns, por exemplo, os outros nobres, como

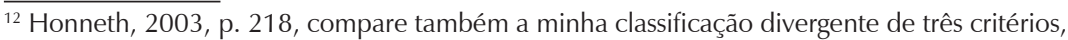
em: Iser, 2008, p. 195 e ss., 274 e ss..
} 
iguais. Além disso, ele precisa atribuir a eles apenas as capacidades de reconhecer adequadamente sua superioridade, e essa característica rudimentar não fundamenta, necessariamente, o mesmo reconhecimento.

No entanto, Honneth também parte do princípio de que questões de legitimidade não se deixam decidir através de acesso direto a necessidades, mas somente através do recurso àquelas razões que contam como "boas" razões dentro das respectivas ordens do reconhecimento estabelecidas historicamente. Pode-se falar de "uma obrigação racional" à inclusão, se as exclusões em uso até agora comprovarem-se como injustificadas à luz dos princípios do reconhecimento aceitos.

Para poder iniciar fundamentadamente um tal processo de inclusão,Honneth acredita necessitar do conceito de "característica valorativa". O sujeito excluído pode, então, declarar: "se essa pessoa foi reconhecida por $X$, eu também quero ser reconhecido por $X$, dado que iguais devem ser tratados de forma igual!". Porém, a partir desse racionício, ainda não se chega ao critério de progresso necessário, porque todos os sujeitos não podem ser, tanto faz quais característias eles possuem, globalmente incluídos. Por isso, Honneth recorre, à maneira kantiana, em última instância, a uma característica que somente a modernidade percebeu de forma adequada, a qual reclama respeito e desde sempre é compartilhada pelos seres humanos: a capacidade humana para autônoma determinação de fins.

Honneth acredita que já o recém-nascido aprende a reconhecer sua pessoa de referência como inteligível, ou seja, como ser autônomo e capaz de compreensão de sentido. Da mesma forma, ele deve perceber, no decorrer de seu desenvolvimento, de forma automática, todos os outros seres humanos como seres humanos. Somente depois pode o sujeito perder esse "reconhecimento prévio" (Honneth, 2005, p. 62). Um tal "Esquecimento-do-reconhecimento" surge através de práticas so- 
ciais autonomizadas ou sistema de convencimento ideológico (Honneth, 2005, p. 71 e ss.). Com certeza, se a criança não reconhecesse, pelo menos, a autonomia da sua pessoa de referência como uma propriedade valorativa central, essa capacidade não poderia ser compreendida por si mesma como a capacidade mais importante. Porém, porque deveríamos compreendê-la como nossa capacidade mais importante? Nesse ponto, há, até hoje, uma lacuna na argumentação de Honneth. Por isso, considero conveniente, recorrer a um argumento de Christine Korsgaard (1996). Somente nossa autonomia possibilita-nos transformar nossas fracas avaliações em fortes avaliações. Precisamos, com isso, no mínimo, ver nossa autonomia como fonte indireta de todos os nossos valores, sejam eles quais forem. Quando seres autônomos desse tipo precisam reconhecer, no mínimo, uma pessoa na sua capacidade para a autonomia, podem-se remeter à "obrigação racional" de igualmente reconhecer todos os outros sujeitos que dispõem dessa capacidade ${ }^{13}$. Se, com a ênfase no nível elementar de inteligibilidade, um motivo kantiano é inserido na teoria do reconhecimento, então, o segundo critério do progresso da individualização está sob um signo hegeliano.

(b) Individualização

Com o segundo critério de progresso da "Individualização", Honneth estabelece a relação mais clara entre sua teoria formal da vida boa e a almejada concepção de progresso. A primeira deve atuar como telos interno da última. Honneth pretende, com isso, compreender como progresso não só a mudança do reconhecimento vinculado a grupos para um reconhecimento individual, mas também a diferenciação das três esferas do reconhecimento. Aqui se deveria trazer para a experiência, no sentido de um processo de aprendizagem, respectivamente, mais sobre as possíveis formas de expressão e as pré-condições da nossa autonomia pessoal.

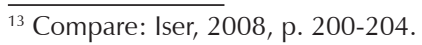


Nesse sentido, a percepção avaliativa deve refinar-se, do mesmo modo como o paladar de alguém que se prepara para ser um conhecedor de vinho. A "autorrealização" como objetivo do reconhecimento tem sido repetidamente criticada, por constituir um valor específico da Modernidade ocidental, o qual não seria útil para uma sociedade multicultural em que, para muitos, a fidelidade a Deus seria mais importante do que o desenvolvimento dos próprios potenciais (Fraser, 2003, p. 46). Honneth, em contraposição, ressaltou que autorrealização significa, num sentido puramente formal, apenas a possibilidade de uma determinada pessoa conduzir estritamente a vida que deseja, sem sentir vergonha em público, portanto, um conceito positivo de liberdade, o qual atribui às condições psíquicas da autonomia uma especial relevância (Honneth, 2003a, p. 209). No entanto, essa tese permite duas interpretações. A primeira ressalta necessidades (i), a segunda, as características valorativas (ii).

Pode-se falar de um progresso moral, quando as necessidades, até então reprimidas, passam a ser permitidas. $\mathrm{O}$ autorrelacionamento autônomo pode-se, certamente, explicar também pela falta de bloqueios inconscientes dos desejos e capacidades já existentes. Nesse sentido, acentua Honneth que a concepção de progresso deve em suma, reverter em favor da grandeza, em razão da qual foi dada tanta atenção ao comportamento do reconhecimento (Honneth, 2003, p. 325), o que, para ele, significa: ao autorelacionamento bem-sucedido. Nós deveríamos partir, por conseguinte, do primado das necessidades, da derivação de deveres das nossas necessidades, a fim de, por fim, falar de um valor? Às vezes, parece que Honneth defende essa posição. Contudo, não é problemático, quando se acredita introduzir progresso moral simplesmente declarando valiosas características até então consideradas sem valor e, por isso, supostamente "reprimidas com razão", a fim de ampliar e "melhorar" a ordem do reconhecimento? 
Não seria o caso, porém, de primeiramente reconhecermos características valorativas, que depois implicam deveres, com os quais necessidades normativas são criadas para serem tratadas de acordo com esses direitos e deveres? Afinal, a um sujeito que tem necessidade de um determinado reconhecimento,não somos devedores deste último, se o sujeito não possuir a propriedade digna de reconhecimento ou incorporaro respectivo valor. Nós não podemos admirar arbitrariamente um pintor mediano, só porque ele tem necessidade de aumentar sua autoestima por meio de elogios.

Entretanto, essa contraposição dicotômica de necessidades e propriedades valorativas não é exatamente útil. Uma sociedade que permite "ver" mais valores não é apenas uma sociedade amplamente valorativa, mas também é povoada por indivíduos que tendem a apresentar força psíquica para a condução de uma vida autônoma, indicando, portanto um maior grau de liberdade positiva. Se a premissa de uma natureza pecadora do ser humano não for aceita, de início, então será preciso justificar cada repressão de impulsos internos. A satisfação de necessidades, portanto, se nenhum argumento importante for contrário, é um argumento em si ou representa um valor. Deveres - aos quais uma teoria crítica que se concentra no sentimento de revolta precisa atribuir o primado somente podem ser explicitados a partir do princípio do reconhecimento recíproco. Porém, quais razões devem ser consideradas aqui como plausíveis - ou, conforme Forst (2007, p. 82), como recíprocas universalmente justificáveis - precisa ser explicado, no mínimo, também em relação às necessidades humanas.

Afinal, poder-se-ia (com Honneth) argumentar que uma sociedade não é apenas "saudável", mas também justa, se os seres humanos possibilitam, na sua atividade do dia-a-dia, o reconhecimento da expressão da criatividade e não só de raras obras de arte de um gênio. Com certe- 
za, são necessárias diferenciações estéticas. Além disso, crítica justificada precisa permanecer possível, ao invés de rapidamente ser compreendida como "desrespeito" (Margalit, 1997, p. 23). Porém, standards críticos podem - especialmente quando surgem com exigência de "normalidade" - sobrecarregar os sujeitos a eles subjugados e os fazer desnecessariamente infelizes. Por isso, deveríamos nos esforçar para desenvolver formas da Crítica-que-abre-mundos. Essa crítica não é importante somente porque diferenciações são em si, necessariamente, algo bom ou digno de ser promovido. Pelo contrário, um conceito de autonomia, que vê na possibilidade da individualização, especialmente, uma libertação da heteronomia, cria o núcleo ético e também formal da concepção de progresso honnethiana. Não se trata, portanto, de um perfeccionismo do desenvolvimento de si, mas de rejeitar o desrespeito mal fundamentado dos próprios impulsos, através da sociedade. Se, por um lado, atribui-se a nossos "desejos de segunda ordem" (Harry Frankfurt), sempre culturalmente intermediados e formadores de identidade institucionalizada, um primado, porque nós, somente em sua luz, decidimos se devemos seguir nossos "desejos de primeira ordem". Por outro lado, esses desejos de primeira ordem podem deixar aparecer tais desejos de segunda ordem como muito repressivos e, com isso, como ilegítimos.

O critério do progresso da individualização indica, assim, uma relação complexa com a estrutura de revoltas morais, porque o processo dessa abertura de mundo se deixa compreender como uma "produção" ou "deslocamento" da revolta. A revolta será "Produzida", quando propriedades antes não respeitadas passam a ser moralmente reconhecidas. Fala-se de "deslocamento", lá onde o que era moralmente definido como um desrespeito, transforms-se, agora, no seu inverso. Por exemplo, a indignação anteriormente exigida diante de uma relação homossexual torna-se uma justa razão para revolta por parte do homosexual. 
Aqui, o processo de individualização fecha algumas possiblidades de revolta, mas abre outras.

\subsection{Crítica da sociedade}

Segundo Honneth, as sociedades deveriam poder ser julgadas no contexto da questão de em que medida possibilitam aos sujeitos que nelas vivem um grau suficiente de reconhecimento e, com isso, uma autorrelação bem-sucedida. Enquanto a filosofia política se define, principalmente, em torno das questões da legitimidade moral-política ou da justiça (Honneth, 2000, p. 22), a disciplina da filosofia social favorecida por ele dedica-se, primeiramente, à determinação das "condições universais de possibilidade" (Honneth, 2000, p. 55) de uma vida boa, a partir das quais seriam derivados, então, os princípios materiais da justiça. Assim, sociedades devem ser consideradas como patológicas quando impõem "limitações estruturais" (Honneth, 2000, p. 22) à realização de uma relação positiva. No entanto, no contexto de uma teoria crítica da sociedade, convém ter cuidado para que a ênfase no critério de progresso da individualização não conduza a uma falsa psicologização da teoria do reconhecimento, como, às vezes, ocorre nos escritos do Honneth.

Em função da tentativa de fundamentar uma teoria material substantiva da justiça em uma teoria formal da vida boa, surge uma ambiguidade na proposta teórica honnethiana. Não fica claro quais são as condições de uma vida autônoma que a teoria do reconhecimento é capaz de abarcar. Essa obscuridade surge, em função do reconhecimento abranger três diferentes níveis, a saber:

- nível central de um status normativo, que se diferenciou triplamente na modernidade. Além disso, é neste nível que irá concretizar-se quais exigências recíprocas decorrem dos respectivos status. A essas exigências correspondem expectativas justificadas. Este nível é central 
para uma teoria da sociedade crítica reconstrutiva, porque ele, a partir dessas expectativas normativas, identifica seu ponto de partida para

- abrir o nível da proteção moral dos aspectos materiais. O conteúdo do que é devido neste nível não se deixa explicar, sem que se refira a esses aspectos materiais, ou seja necessidades ou interesses. Essas necessidades e interesses não compreendem apenas os basaiscorporais e interativos de que tratei na seção 2.1 , mas também - se partimos da capacidade humana para autonomia - todas as condições que nos capacitam para a autonomia, ou seja, para o julgamento autônomo, bem como o agir autônomo. Existe, porém,

- um nível de retroalimentação ${ }^{14}$, que complica o quadro, sobre o qual ambos os primeiros níveis interagem. Quando somos desrespeitados no nosso status normativo, pode-se descrever esse fato de duas formas. Primeiramente, isso tem consequências psicológicas

\footnotetext{
${ }^{14}$ Em alemão, a palavra utilizada é Rückkopplung. É uma palavra composta de duas partes: Kopplung que significa, na tradução literal dos dicionários: "acoplamento, copulação" (Dicionário de Alemão-Português, Porto: Porto Editora, 1986. P. 511) e Rück que é um prefixo que designa algo voltado para trás, como em Rücken, que significa: "costas" (Dicionário de Alemão-Português, Porto: Porto Editora, 1986. P. 660). Portanto, é sempre utilizado em verbos e substantivos para a eles atribuir um sentido de retorno, volta, passado ou de fazer novamente como, no português, o prefixo "re" de "refazer", que tem função semelhante. Portanto, rückkopplen significaria "acoplar retroativamente, regenerar, realimentar" (Dicionário de Alemão-Português, Porto: Porto Editora, 1986. P. 661). Por vezes, o autor parece querer utilizar a expressão em sentido similar ao que Luhmann dá ao termo Kopplung, ou seja, o de acoplamento estrutural entre dois sistemas, que aumenta a intensidade da interação no ponto interseccionado (Ver, por exemplo, Luhmann, Niklas. Das Recht der Gesellschaft. Frankfurt am Main: Suhrkamp, 1995, Kap. 10: Strukturelle Kopplungen. Ver, também, o significado dado ao termo pelos dicionários sobre a teoria de Luhmann, por exemplo: Krause, Detlef. Luhmann-Lexicon. Stuttgart: Ferdinand Enke, 1999. Pp. 45-50 e Corsi, Giancarlo; Esposito, Elena; Baraldi, Claudio. Glosario sobre la teoría Social de Niklas Luhmann. México: Universidad Iberoamericana/Iteso/Anthropos, 1996. Pp. 19-21) e, por isso, o tradutor, em um primeiro momento pensou em adotar, simplesmente, o termo acoplamento, mas, por outro lado, o autor parece sempre querer dar a ideia de retroalimentação entre os níveis, ou seja, de interação ativa entre as duas outras dimensões por ele esboçadas, então, optou-se pelo termo retroalimentação, por entender-se que retrata de forma mais adequada a ideia do autor (Nota do tradutor).
} 
para nossa autorrelação e, com isso, sobre as condições psíquicas da nossa autonomia em ambas as dimensões do julgamento e da ação. Elas formam, no nível 2, um importante, mas, de fato, somente um aspecto material da proteção moral. Em segundo lugar, mostra uma lesão do nosso status normativo, ou seja, que sofremos uma injustiça, independentemente de quais de nossas necessidades ou interesses do nível 2 tenham sido lesionadas.

Partindo do fato de que o desrespeito a expectativas normativas (e, com isso, do status normativo) do nivel 1, através da retroalimentação no nivel 3, implica efeitos psíquicos sobre nossa autorrelação, Honneth parece, às vezes, concluir que a proteção desse autorrelacionamento representa $\mathrm{o}$ único aspecto material da proteção moral do nível 2. A teoria "formal" da vida boa, sobre a qual sua filosofia social deveria repousar, segue aqui, pelo menos implicitamente, o discurso de Ernst Tugendhat de um conceito formal de saúde psíquica (Tugendhat, 1984, p. 52), que é explicitada em contraste com a "lesão da capacidade funcional do querer" (Tugendhat, 1984, p. 55).

Moral e justiça são, porém, compreendidas de forma muito estreita, quando se determina como sua única tarefa a proteção de nossa autorrelação. Por conseguinte, eu duvido que

[a] justiça ou o bem-estar da sociedade [...] sejam medidos pelo nivel de sua capacidade, de proteger as condições de reconhecimento recíproco, dentre os quais a formação da identidade pessoal e, com isso, a realização individual de si se realizam de uma forma positiva (Honneth, 2003a, p. 206, grifo nosso).

Se se compreendem as passagens citadas, e parece ser o que Honneth faz, como conteúdo daquilo que pode ser atribuído à moral, então, perdem-se de vista, com essas determinações, aspectos centrais daquele nível (2), os quais tratam dos aspectos materiais da proteção moral.

Então, não queremos ter Educação (Bildung.) simplesmente porque sem essa nos sentiríamos desrespeitados, ou seja, para evitar sofrimento psíquico. Na verdade, é exatamente o contrário: justamente porque 
Educação é um valor central para nós, acreditamos, dever-nos reciprocamente sua disponibilização. Apenas à luz dessas exigências apresenta-se a privação por parte da sociedade como um desrepeito. Reconhecimento pode apresentar-se no nível de retroalimentação como um "bem fundamental comunicativo" (Honneth, 2001, p. 109), porque precisamos dele como condição psíquica de nossa liberdade, embora precisemos ainda de outras condições. Essas estão implícitas no status do reconhecimento, porém ainda não explícitas. Por isso, são necessárias considerações materiais complementares no nível 2, que compreendam em toda a extensão as condições de uma autônomia e, em última análise, boa vida.

Nancy Fraser acusou Honneth, nesse sentido, também de encurtar a teoria da justiça, porque ele deixava de fora as questões da distribuição. Fraser tem o receio de que "Política de Identidade", já muito influente politicamente nos U.S.A, na metade dos anos noventa, deslocasse da agenda política, de forma duvidosa, o tema no mínimo igualmente relevante da distribuição. Essa ideia deixa-se guiar pela intuição de que, para poder valer como um integrante da sociedade com iguais direitos, seriam necessárias não só uma autorrelação bem sucedida, mas também pré-condições materiais e cognitivas, a saber: bens fundamentais como dinheiro, alimentação, roupas ou educação. Com isso, Fraser insiste, contra Taylor e Honneth, em que somente reconhecimeto e distribuição conjuntamente proporcionam justiça no sentido de participação em igualdade de direitos na vida pública. Enquanto distribuição garante as condições objetivas de um tal ideal de justiça da "paridade participativa", reconhecimento assegura as suas condições intersubjetivas (Fraser, 2003, p. 55). Com isso, ela acusa a teoria honnethiana de um "estreitamento culturalístico".

Em face dessa crítica, Axel Honneth insistiu em que o conceito de Reconhecimento poderia - se for adequadamente diferenciado - compreender também questões de desigualdade de distribuição. Em primeiro lugar, o nosso entendimento daquilo que devemos aos outros em razão do seu status normativo como ser-humano autônomo e em igualdade de 
direitos ampliou-se historicamente e passou a compreender também direitos sociais. Por conseguinte, as partes envolvidas podem sustentar que a elas competiria uma mínima medida de bens fundamentais, de acordo com a política de dignidade, como cidadãos iguais, portanto, a fim de que eles possam utilizar também faticamente as suas liberdades jurídicas. Em segundo lugar, eles podem se referir ao critério do desempenho, a fim de reclamar uma adequada indenização por seu trabalho, porque esse é constitutivo para o capitalismo, assim como (também) é uma construção cultural. Somente ao entender esse tipo de distribuição como um problema de reconhecimento, se poderia, de fato, esclarecer porque os seres humanos se revoltam: porque eles se sentem atingidos na sua identidade, a saber, através de uma injustiça perceptível. O que vale como injustiça depende, por consequência, das nossas expectativas de reconhecimento: justiça e reconhecimetno esclarecem-se mutuamente.

Na discussão entre Honneth e Fraser permanece, porém, desconcertantemente obscuro se, com "desrespeito", se quer dizer uma lesão qualquer do status normativo (1) ou simplesmente os efeitos psíquicos no nível da retroalimentação (3). Em grande parte de sua obra, Honneth refere-se ao nível (3), enquanto considera implicíto, no debate com Fraser o nível (1). Independentemente de percebermos uma injustiça, ela viola nosso status normativo. Porém, por mais que esta resposta seja acertada, ainda assim não se resolve o problema de que as circunstâncias morais relevantes não se reduzem ao nível de retroalimentação. Com certeza, o argumento de Fraser apresenta uma fraqueza. Contra o posicionamento do desrespeito nos efeitos psíquicos, ela opta por um status-conceito de reconhecimento (idem: p. 47). De fato, a sua ideia-guia da paridade participatória pode ser lida como explicação do que significa reconhecer alguém como cidadão igual ou pessoa moralmente igual. Mas, então, ela deveria entender também uma distribuição injusta como desrespeito, porque uma distribuição injusta viola meu status como pessoa com direitos iguais. Exatamente a esse ponto, Honneth se refere em sua resposta. 
Fraser não deveria, por isso, de maneira alguma, compreender questões do reconhecimento e aquelas de distribuição como dois aspectos diferentes de uma justiça entendida deontologicamente.

De fato, somente um conceito de reconhecimento no sentido de (1) é abrangente o suficiente para carregar o peso a ele imposto. Com certeza, vamos experienciar ações injustas também como desrespeito psiquicamente relevante, que nos atinge no nosso autoentendimento. Exatamente sobre essa ideia se funda a plausibilidade de uma luta por reconhecimento como motor do progresso moral. Porém, o fato de experienciamos cada injusto no modo de desrespeito não significa, absolutamente, que cada injusto se reduza, conteudisticamente, ao aspecto do violar da psique.

De mais a mais, nós não precisamos experienciar o injusto nesse modo, porque, na armadilha da doutrinação ideológica, não se chega a qualquer retroalimentação. Honneth não diferencia, por conseguinte, suficientemente entre sentimentos de desrespeito como

(1') modus centrais psíquicos da experiência do desrespeito do status no nível (1), que podem se referir a todos os aspectos materiais do nível (2), e (3') as causas responsáveis pelo abalo das condições psíquicas da autonomia no nível (3), o que se poderia descrever como uma violação de um específico aspecto material do nível (2).

Se o desrespeito no caso (3') está para o conteúdo de um inconveniente $\mathrm{A}$ (causas psiquicamente desastrosas), que se mostram como uma retroalimentação de um outro inconveniente B, então, ele está no caso (1') somente para o modo do experienciar o inconveniente B passível de ser descrito como independente de A (por exemplo, de um assalto, que já apresenta em si uma injustiça). Pode-se perceber, aqui, que não é a necessidade psíquica de reconhecimento que esclarece nossas exigências de reconhecimento, pois a relação é exatamente ao contrário ${ }^{15}$. Se esta

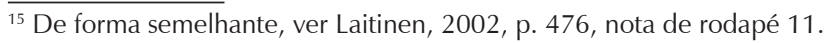


crítica é correta, então, abarca uma teoria que se interessa somente de forma indireta pelo nível de retroalimentação por reconhecimento como condição psíquica da autonomia de todas as injustiças, porque esse nível de retroalimentação se refere ao nível normativo do ser-reconhecido e, com isso, per definitionem, abrange todos os desrespeitos ( 1 '). Porém, com isso, não esclarece o nível de retroalimentação - pois trata, nos fenômenos considerados, de desrespeitos -, antes o pressupõe.

Injustiças não se deixam esclarecer por meio de efeitos psíquicos, mas somente através da referência de que uma determinada ação ou postura não nos reconhece adequadamente no nosso status normativo como pessoa(de direito) autônoma, como parceiro de cooperação ou como sujeito amado ou amigo. Aqui, são necessários argumentos normativos e não psicológicos. Com isso, não se deve negar que necessidades psíquicas possam funcionar como argumentos - o que eu defendi acima na discussão do critério de individualização na seção 2.2. Porém, já a dissociação de diferentes tipos de necessidades na seção 2.1 deveria ter deixado claro que somente aquelas exigências decorrentes do nosso status normativo são o ponto de partida para uma teoria crítica - ainda quando esse status se refira a uma multiplicidade de necessidades cuja satisfação deveria salvaguardar. Somente quando a teoria crítica permanece consciente da aqui esboçada retroalimentação entre expectativas normativas e necessidades psíquicas, ela poderá ir de encontro ao perigo de uma diagnose unilateral de inconvenientes modernos.

As expectativas centrais normativas, a cuja violação os sujeitos reagem com revolta, não são simplemente pretensões de validade como em Habermas, mas tampouco são pretensões de identidade como em Honneth (1992, p. 82); são, antes, pretensões de status. Qual é, exatamente, a diferença entre os três conceitos? Todos os três contêm, através da palavra "pretensões", em última análise, a referência a demandas normativas. O uso habermasiano de "pretensões de validade" refere-se a argumentos. Ele significa, somente, que se devem fundamentar com razões 
suas afirmações; a ele subjaz, portanto, um outro conceito de normatividade. Que identidades produzam reivindicações, tem, por outro lado, a vantagem de que esse conceito relaciona-se a pessoas específicas. No entanto, essa forma de falar soa como se uma identidade gerasse razões a partir de si mesma, a despeito do quê e perante quem. O conceito de Status faz referência mais forte, pelo contrário, a práticas compartilhadas, nas quais pessoas se encontram umas com as outras em determinadas relações normativas. Nesse contexto, quer-se dizer com status, primeiramente, aquela descrição também desigual de determinados direitos ou deveres, de acordo com os quais nós somos reconhecidos em uma determinada ordem, por exemplo, também teocrática. O respectivo status é definido através de expectativas morais intersubjetivas que, seguramente, são influenciadas por identidades, porém, não são por elas fixadas. A frustração dessas expectativas pode conduzir àresistência. Da mesma forma, essas expectativas valem, no mínimo, nos respectivos contextos, como fundamentadas, porém, podem ser também colocadas em dúvida. Somente o conceito de status do reconhecimento deontológico indica, de um lado, aquele conteúdo normativo que uma teoria crítica necessita, e torna possível, de outro lado, a criação de uma ponte para aqueles motivos que podem conduzir a uma luta por reconhecimento.

2.4 Revolta e Resistência A teoria crítica sempre quis esclarecer o mecanismo psíquico da resistência, que poderia conduzir à superação dos problemas diagnosticados. Uma vez que, segundo Honneth, as experiências de falta de reconhecimento ou até de desrespeito machucam os sujeitos em sua identidade, deveriam os atingidos, de forma especial, estar motivados à resistência, a uma "luta por reconhecimento". E essa luta, que, de forma nenhuma, precisa ser disputada de forma violenta (pense-se somente na luta índica pela libertação de Mahatma Gandhi), deveria causar um progresso moral em direção a relacionamentos de reconhecimento cada vez mais justos (Honneth, 1992, cap. 8). Honneth queria, portanto, mostrar que existe uma instância, à qual se pode sempre 
apelar, na esperança de que ela seja capaz de pressionar o status quo digno de crítica.

Porém, a resistência deixa-se realmente (primariamente) significar como resposta a uma experiência do desrespeito pessoal - seja através de outras pessoas ou instituições? Contra a concepção honnethiana de lutas sociais por reconhecimento podem-se levantar três objeções. Essas, eu designo de problema da intensidade (a); Dilema-do-Esclarecimento-da-Motivação (b); e problema do representante (c). Novamente, elas remetem à necessidade de abarcar o conceito de reconhecimento de forma suficientemente ampla.

O problema da intensidade diz respeito à pergunta sobre se a teoria do reconhecimento realmente tem êxito em abarcar todas as experiências de desrespeito como danos à integridade psíquica. Com certeza, o roubo de um automóvel por parte de um criminoso que não conhece a vítima representa um injusto. Porém, trata-se, exatamente por isso, de um desrespeito intencional, que lesiona a vítima pessoalmente (Gosepath, 2004, p. 105)? Pois bem, acima eu já argumentei no sentido de que todas as injustiças podem ser compreendidas como desrespeito ao nosso status normativo como iguais, como companheiro solidário ou como pessoa amada ou amiga. Com certeza, a intensidade da lesão da integridade sentida variará conforme a gravidade da intencionalidade ou injustiça. Como foi exposto na seção 2.3, não se deve orientar muito no telos material da identidade psíquica, mas experiências de desrespeito devem muito mais ser apreendidas como indícios de injustiças eurísticamente plenos de valor. Então, significam também pequenos abalos a possíveis inconvenientes. Isso também vale para a experiência de uma carro roubado.

(b) porém, a ideia, de que pessoas revoltam-se com um desrespeito não exige, mesmo assim, uma personalização problemática de estruturas anônimas? Quem, por acaso, se sente humilhado por estruturas sociais? Disso, parece resultar para o teórico crítico do reconhecimento um Dilema-do-Esclarecimento-da-Motivação. Quanto mais ele quer motivar os destinatários com sua análise, mais ele deveria precisar simplificar os 
complexos abstratos da sociedade. Uma tal personalização deveria apresentar um obstáculo para a tentativa de mudar de forma efetiva as estruturas causais. Além disso, a partir daqui, surgiria o perigo de se atribuir a pessoas ou grupos uma culpa moral, que a eles não compete. Se, ao contrário, se quiser levar em conta a complexidade das sociedades modernas com suas múltiplas responsabilidades, então, não se conseguirá, frequentemente, mostrar nenhum fenômeno claro de desrespeito intencional, muito menos fenômenos de desrepeito institucional (que, porém, existem como, por exemplo, na armadilha de um racismo institucional). Também os conselhos de administração de multinacionais que, frequentemente, demitem funcionários podem não querer isso dessa maneira e agir sob a pressão de imperativos econômicos (por exemplo dos shareholder-value). Quando, porém, as injustiças centrais da contemporaneidade são atribuíveis a estruturas anônimas, das quais, frequentemente, nem mesmo as cidadãs e os cidadãos de um estado particular são responsáveis democraticamente, então, coloca-se a pergunta essencial sobre qual força motivacional uma teoria do reconhecimento pode ainda liberar.

Porém, já as premissas são, no entanto, inexatas. Com certeza, pode-se revoltar contra instituições injustas e, nesse sentido, sentir-se desrespeitado. Precisa-se, simplesmente, compreender o conceito de reconhecimento de tal forma que ele permita apreender injustiças institucionals como desrespeito. Neste caso, não se chega de forma alguma ao Dilemado-esclarecimento-da-motivação. Uma instituição injusta ou uma estrutura anônima, embora possa ou deva ser modificada pelos seres-humanos, desrespeita aqueles por ela discriminados. E somente faz sentido partir-se de diversas formas e de diferentes intensidades de injustiças, no contexto de uma teoria do reconhecimento suficientemente diferenciada. A intensidade das lesões sentidas e da revolta resultante assume, com certeza, uma importante função heurística. Porém, ela deveria ser influenciável através da análise social crítica. 
O problema do representante remete-nos, igualmente, a uma dificuldade com a qual toda a teoria se vê confrontada,de que ela conta com a revolta da vítima em razão de uma lesão da identidade. Primeiramente, parece que essa teoria não tem nenhum lugar para a revolta moral diante de uma injustiça contra outros sujeitos, até estranhos. Mas, obviamente, pode haver lutas, nas quais indivíduos ou grupos se empenhem pelos direitos de outros. Poder-se-ia, até mesmo, sugerir que somente essas seriam lutas realmente motivadas moralmente, porque a pessoa não se vê obrigado a agir, à desobediência civil, em favor do próprio bem-estar, mas unica e exclusivamente em razão da lesão de princípios de justiça (Moore, 1982, p. 66).

Aqui, poder-se-ia, por um lado, responder que, nestes casos, os atores da luta se identificam tanto com suas vítimas ou se vêem tanto como potenciais vítimas de amanhã, que eles valoram os ataques contra os outros como ataques contra si mesmos. Psicologicamente, esse deveria permanecer, no entanto, como um caso especial. Além disso, não se trata aqui, absolutamente, de um ato genuíno de revolta moral. No mínimo, porém, coloca a ideia da identificação no sentido correto. Cada reconhecimento é intermediado através de uma norma ou de um completo sistema normativo. O sentimento de revolta funda-se no conhecimento geral sobre quais expectativas de reconhecimento devem ser respeitadas. Assim, a revolta em relação a uma injustiça contra mim remete internamente a possíveis injustiças perante outros. Em relação a essa expectativa normativa generalizada, é, exatamente, a injustiça que torna impossível para aqueles que lutam, se relacionar com a coletividade de forma clara e leal. Também isso tem algo a ver com a suas identidades práticas: aqueles que lutam não se reconhecem a si mesmos nas instituições com seus valores e ideais. Somente quando se compreende as lutas por reconhecimento não somente como defesa da própria identidade é que se apreende a posição daqueles críticos, que não são subjugados.

Em razão dessa compreensão mais abrangente de lutas por reconhecimento precisam também ser relativizadas as desconfianças, que 
Honneth, desde o início, levantou contra os novos movimentos sociais. A esperança de Habermas em relação a uma classe média pós-convencional, ou seja, em relação à sensibilidade daqueles que podem bancar (Honneth in Habermas, 1985, p. 199) era avaliada por Honneth como desligamento categorial de todas aquelas experiências de injustiça que ainda seriam sofridas pelas classes baixas. Essa é uma visão curta, quando se pensa que essas "sensibilidades", nos anos sessenta e setenta - como hoje ainda no Attac - se referem a injustiças globais. A consciência moral pós-convencional, de fato, já deveria permitir aos sujeitos se revoltarem contra o sofrimento dos outros e, então, conduzirem uma militante luta por reconhecimento.

A experiência psíquica do desrespeito é, portanto, um modo importante da descoberta de injustiças - e, nesse sentido, a crítica social precisa se ocupar muito mais fortemente com ela. No entanto, ela não é nem segura, nem o único modo. Não é segura, porque nós não experienciamos muitas injustiças, das quais nos tornamos vítimas, psiquicamente como desrespeito. Assim, podemos ser criados com expectativas baixas ou aceitamos, falsamente, em razão de estruturas anônimas, restrições que, para além de questões de justiça, para nós, conjuram, simplesmente, falta de sorte.

A experiência psíquica de desrespeito não é, além disso, o único modo para se descobrir injustiças, porque também podemos reconhecer injustiçassem que nós mesmos tenhamos sido atingidos por elas. Através das minhas respostas às três possíveis objeções, a relevância das necessidades psíquicas por reconhecimento para o esclarecimento da resistência do mundo interior não foi negada. Porém, o olhar foi aberto para uma concepção mais abrangente de reconhecimento do nosso status normativo, à qual correspondem o sentimento de revolta, assim como aquele da humilhação.

Se se resumem as formas, nas quais a teoria de Honneth preenche as quatro tarefas da crítica da sociedade que eu esbocei no início deste artigo, então mostra-se que, apesar da sua enorme força de inovação, o 
acento muito forte da teoria formal do bem conduz a uma excessiva limitação do âmbito fenomênico da crítica da sociedade. Somente o sentimento de revolta é capaz de servir de chave, para abrir a nós uma análise adequada de todas as experiências de desrespeito social.

\section{Referências}

FORST, Rainer (2004). Moralische Autonomie und die Autonomie der Moral. In: FORST, Rainer. Das Recht auf Rechtfertigung. Elemente einer konstruktivistischen Theorie der Gerechtigkeit. Frankfurt/M.: Suhrkamp, 2007, p. 74-99.

FRASER, Nancy. Soziale Gerechtigkeit im Zeitalter der Identitätspolitik. Umverteilung, Anerkennung und Beteiligung. In: FRASER, N.; HONNETH, Axel. Umverteilung oder Anerkennung? Eine politisch-philosophische Kontroverse. Frankfurt/M.: Suhrkamp, 2003, p. 13-128.

GOSEPATH, Stefan. Gleiche Gerechtigkeit. Grundlagen eines liberalen Egalitarismus. Frankfurt/M.: Suhrkamp, 2004.

HABERMAS, Jürgen. Dialektik der Rationalisierung, In: HABERMAS, Jürgen. Die neue Unübersichtlichkeit. Kleine politische Schriften V. Frankfurt/M.: Suhrkamp 1985, p. 167-208.

HONNETH, Axel. Kampf um Anerkennung. Zur moralischen Grammatik sozialer Konflikte. Frankfurt/M.: Suhrkamp, 1992.

HONNETH, Axel. Pathologien des Sozialen. Tradition und Aktualität der Sozialphilosophie. In: HONNETH, Axel. Das Andere der Gerechtigkeit. Aufsätze zur praktischen Philosophie. Frankfurt/M.: Suhrkamp 2000, p. 11-69.

HONNETH, Axel. Rekonstruktive Gesellschaftskritik unter genealogischem Vorbehalt. Zur Idee der ,Kritik' in der Frankfurter Schule. In: HONNETH, Axel. Pathologien der Vernunft. Geschichte und Gegenwart der Kritischen Theorie. Frankfurt/M.: Suhrkamp, 2007, p. 57-69.

HONNETH, Axel. Leiden an Unbestimmtheit. Eine Reaktualisierung der Hegelschen Rechtsphilosophie. Stuttgart: Reclam, 2001.

HONNETH, Axel. Der Grund der Anerkennung. Eine Erwiderung auf kritische Rückfragen. In: HONNETH, Axel. Kampf um Anerkennung. Zur moralischen Grammatik sozialer Konflikte, erw. Ausg. Frankfurt/M.: Suhrkamp 2003, p. 303-341.

HONNETH, Axel. Umverteilung als Anerkennung. Eine Erwiderung auf Nancy Fraser. In: FRASER, Nancy; HONNETH, Axel. Umverteilung oder Anerkennung? 
Eine politisch-philosophische Kontroverse. Frankfurt/M.: Suhrkamp, 2003a, p. 129-224.

HONNETH, Axel. Die Pointe der Anerkennung. Eine Entgegnung auf die Entgegnung. In: FRASER, Nancy; HONNETH, Axel. Umverteilung oder Anerkennung? Eine politisch-philosophische Kontroverse, Frankfurt/M.: Suhrkamp, 2003b, p. 273-307.

HONNETH, Axel. Das Recht der Freiheit. Grundriß einer demokratischen Sittlichkeit. Berlin: Suhrkamp, 2011.

ISER, Mattias. Empörung und Fortschritt. Grundlagen einer kritischen Theorie der Gesellschaft. Frankfurt/M.: Campus, 2008.

ISER, Mattias. Honneth und die Gewalt der Missachtung. In: KUCH, Hannes; HERRMANN, Steffen K. (Hg.). Philosophien sprachlicher Gewalt. Weilerswist: Velbrück, 2010, p. 387-407

KORSGAARD, Christine M. The Sources of Normativity. Cambridge: UP, 1996.

LAITINEN, Arto. Interpersonal Recognition. A Response to Value or a Precondition of Personhood?. Inquiry, Oslo, v. 45 n. 4, 2002, p. 463-478.

MACINTYRE, Alasdair. Die Anerkennung der Abhängigkeit. Über menschliche Tugenden, Hamburg: Rotbuch, 2001.

MARGALIT, Avishai. Die Politik der Würde. Über Achtung und Verachtung. Berlin: Fest, 1997.

MOORE, Barrington. Ungerechtigkeit. Die sozialen Ursachen von Unterordnung und Widerstand. Frankfurt/M.: Suhrkamp, 1982.

RORTY, Richard. Vier Formen des Schreibens von Philosophiegeschichte. In: RORTY, Richard. Wahrheit und Fortschritt. Frankfurt/M.: Suhrkamp, 2000, p. 355-394.

STRAWSON, Peter F. Freiheit und Übelnehmen. In: POTHAST, Ulrich (Hg.). Seminar: Freies Handeln und Determinismus. Frankfurt: M.: Suhrkamp, 1978, p. 201-233.

TAYLOR, Charles. (1992) Die Politik der Anerkennung. In: TAYLOR, Charles. Multikulturalismus und die Politik der Anerkennung hg. von Amy Gutmann. Frankfurt/M.: Fischer, 1993, p. 13-78.

TOMASELLO, Michael. Die kulturelle Entwicklung des menschlichen Denkens. Frankfurt/M.: Suhrkamp, 2002.

TUGENDHAT, Ernst. (1980)Antike und moderne Ethik. In: TUGENDHAT, Ernst. Probleme der Ethik. Stuttgart: Reclam, 1984, p. 33-56.

Recebido em: 14/03/2013

Aceite final: 10/07/2013 